\title{
Factors in daily physical activity related to calcaneal mineral density in men
}

\author{
TERESA M. HUTCHINSON, ROBERT T. WHALEN, \\ TAMMY M. CLEEK, JOHN M. VOGEL, and SARA B. ARNAUD \\ Life Sciences Division, \\ NASA Ames Research Center, \\ Moffett Field, CA 94035-1000; and \\ University of California Medical School, \\ Davis, CA 95616
}

\begin{abstract}
HUTCHINSON, T. M., R. T. WHALEN, T. M. CLEEK, J. M. VOGEL, and S. B. ARNAUD. Factors in daily physical activity related to calcaneal mineral density in men. Med. Sci. Sports Exerc, Vol. 27, No. 5, pp. 745-750, 1995. To determine the factors in daily physical activity that influence the mineral density of the calcaneus, we recorded walking steps and the type and duration of exercise in 43 healthy 26-to $51-\mathrm{yr}$-old men. Areal $\left(\mathrm{g} \cdot \mathrm{cm}^{2}\right)$ calcaneal bone mineral density (CBMD) was measured by single energy $x$-ray densitometry (SXA, Osteon, Inc., Wahiawa, HI). Subjects walked a mean ( \pm SD) of $7902( \pm 2534)$ steps per day or approximately $3.9( \pm 1.2)$ miles daily. Eight subjects reported no exercise activities. The remaining 35 subjects spent 143 (2-772) (median and range) $\mathrm{min} \cdot \mathrm{wk}^{-1}$ exercising. Twenty-eight men engaged in exercise activities that generate single leg peak vertical ground reaction forces $\left(G^{2} F_{z}\right)$ of 2 or more body weights (high loaders, HL), and 15 reported exercise or daily activities that typically generate $\mathrm{GRF}_{2}$ less than 1.5 body weights (low loaders, LL). CBMD was $12 \%$ higher in HL. than LL $\left(0.668 \pm 0.074 \mathrm{~g} \cdot \mathrm{cm}^{-2}\right.$ vs $\left(0.597 \pm 0.062 \mathrm{~g} \cdot \mathrm{cm}^{2}, P<0.004\right)$. In the HL group, CBMD correlated to reported minutes of high load exercise $(\mathrm{r}=0.41, P<$ $0.03)$. CBMD was not related to the number of daily walking steps $(N$ $=43, \mathrm{r}=0.03, \mathrm{NS})$. The results of this study support the concept that the dominant factor in daily physical activity relating to bone mineral density is the participation in site specific high loading activities, i.e., for the calcaneus, high calcaneal loads.
\end{abstract}

BONE MINERAL DENSIT'Y, MUSCULOSKELETAL LOADING, ACTIVITY LEVEL, ACTIVITY EVALUATION, SINGLE ENERGY X-RAY DENSITOMETER, STEPMETERS

A variety of methods for quantifying daily physical activity level have led to different conclusions regarding the effect of activity level on bone density. Questionnaire data and readings from pedometers, activity meters, and accelerometers are normally converted to estimates of daily energy expenditure. Other methods of categorizing activity level include frequency of weekly exercise (times per week), duration of

(1) $195-9131 / 45 / 2715-(1745833(10 \%)$

MEDICINE: AND SCIENCE IN SPORIS AND EXERCISE

Copyriglt 1905 by the American College of Sports Medicine

Submitted for publication Oetober 1093.

Accepted for publication September 1944. weekly exercise $\left(\mathrm{h} \cdot \mathrm{wk}^{-1}\right)$, level of participation (measure of intensity), and aerobic vs anaerobic activity. These methods provide little information about the musculoskeletal forces imposed on the skeleton at selected bone sites. For example, classifying activity on the basis of aerobic vs anaerobic (muscle building) activity would group running, swimming, and cycling together even though these may develop very different levels of skeletal loading at different anatomical sites.

The objective of this study was to investigate the influence of daily activity on bone density in terms of estimates of site specific cumulative musculoskeletal loading. Toward our goal of developing functional relationships between mechanical loading and bone density, we quantified daily physical activity in terms of activities that load the calcaneus. We selected the calcaneus for bone mineral measurements because of its established sensitivity to loss of mineral during inactivity (5) and its accessibility to the forces applied to it by individual subjects during activity (21).

\section{METHODS}

\section{Subjects}

Fifty three healthy, 26- to 51-yr-old men consented to participate in a 9-wk study approved by the Human Research Experiments Review Board (HRERB) at NASA Ames Research Center and in accordance with the policy statements of the American College of Sports Medicine. Subjects (nonsmokers) were screened for the study by a medical examination to exclude renal, skeletal, gastrointestinal, or cardiac disease. We elected to study only men with shoe sizes between 9 and 10-1/2 to minimize anthropometric differences in bone structure and biomechanical issues of scaling of size. Subjects were asked to maintain their usual work and exercise activities for the duration of the 9-wk study. All subjects completed 
TABLE 1. Median percent error in stepmeters worn by 10 adult men walking on different surfaces at different speeds

\begin{tabular}{llc}
\multicolumn{1}{c}{ Distance/Surface } & Speed & Median (Range) \\
$\begin{array}{l}\text { 0.25-mile walkivaried } \\
\text { 100 feet/level hard }\end{array}$ & Normal & $1.0(0.2-26.6)$ \\
\multicolumn{1}{c}{ surface } & Slow & $3.9(0.3-19.0)$ \\
& Normal & $0.7(0.0-4.7)$ \\
& Fast & $0.3(0.0-4.3)$ \\
100 teet/level soft surface & Slow & $6.5(0.3-44.3)$ \\
& Normal & $1.2(0.3-11.7)$ \\
4 flights/upstairs & Fast & $0.5(0.0-11.3)$ \\
4 flights/downstairs & Normal & $8.0(0.0-20.8)$ \\
& Fast & $4.0(1.3-32.1)$ \\
& Normal & $1.7(0.0-13.0)$ \\
& Fast & $4.7(0.7-25.3)$
\end{tabular}

the study; however, data from 10 individuals could not be used because of unreliable records of current activity, i.e., invented or unreadable $(N=4)$, weight loss exceeding 30 lbs within 6 months prior to the onset of the study $(N=$ 2 ), and acknowledged large changes in daily exercise patterns during the study compared with the 6-month and 1-yr histories, i.e., completely stopping an exercise program $(N=4)$.

\section{Methods for Quantifying Physical Activity}

Past activity history was documented with a modified version of The Minnesota Leisure Time Activity Questionnaire (17), that excluded determination of average daily energy expenditure but included participation in high school, college, or intramural sports. Each volunteer was interviewed to identify recent changes in physical condition such as weight loss and to determine the consistency of past and current physical activities.

Digital stepmeters recording steps (Walkmate, Micronta, Fort Worth, TX) were worn daily, at the waist, during all walking activities. Subjects were instructed to wear the stepmeter at all times during walking related activities such as gardening, golf, exercise walking, etc., but not during nonwalking activities, for example, running/jogging, cycling, swimming, weightlifting, racquet sports, etc. Stepmeters were checked weekly for accuracy within $\pm 2 \%$ by walking a fixed number of steps on a level surface. During the study seven stepmeters were replaced due to damage $(N=4)$ or loss $(N=3)$.

The performance of stepmeters was checked by determining the error in stepmeters by 10 subjects who were not part of the study (Table 1). The 10 subjects walked on different surfaces and up or down stairs at two or three gait speeds. Except for occasional subject-specific variability in gait, the results were consistent. The median percent error was $1.0 \%$ (range $=0.2 \%-26.6 \%$ ) for an "all terrain" quarter-mile walk; 9 of the 10 subjects had an absolute error equal to or less than $3.4 \%$.

A $3^{\prime \prime} \times 5^{\prime \prime}$ activity and exercise log book was given to each subject on the 1st and 9th week of the study to record all daily activities for 7 consecutive days. Descriptive information on the type and duration of activities (i.e., sitting, standing, walking, sleeping, sport) was recorded in 3-h intervals. Number of walking steps for each 3-h interval was also recorded.

For the remaining $7 \mathrm{wk}$ a $6^{\prime \prime} \times 5^{\prime \prime}$ card, folded to fit into a pocket, was given to each subject to record daily stepmeter values and the type of exercise, duration of exercise, and distance, if applicable. To minimize ambiguities between normal daily walking and "walking-like" exercise, subjects were asked to log any activity they considered exercise and to note whether the stepmeter was worn. All stepmeter recordings were treated as daily walking steps. Therefore, daily activity was divided into daily walking steps and nonwalking activities or exercise. Cards were turned in each week and an informal interview was conducted to address any problems and assess subject compliance.

\section{Calcaneal Bone Mineral Density}

A single energy $x$-ray densitometer (SXA, Osteon, Inc. Wahiawa, HI) was used to measure areal $\left(\mathrm{g} \cdot \mathrm{cm}^{-2}\right)$ calcaneal bone mineral density (CBMD) (19). The right calcaneus was measured three times (at 1,5 , and $9 \mathrm{wk}$ ) and the left twice (at 1 and $9 \mathrm{wk}$ ). Bone mineral density values were obtained at the central portion of the calcaneus comprising $2.7 \mathrm{~cm}$ of its length at a location consistently shown to have the lowest mineral density of this bone (19). The precision of the method was determined from the three scans of the right calcaneus of 43 subjects assuming CBMD would not change in $9 \mathrm{wk}$ in individuals engaged in routine daily activities. The mean coefficient of variation $( \pm S D)$ in the three measurements was $0.91 \%( \pm 0.60 \%)$

\section{Data Analysis}

Our purpose in this study was to establish a method of quantifying physical activity in terms of daily walking, nonwalking low-load activity, and nonwalking high-load activity when viewed from the perspective of forces exerted on the calcaneus. In this regard, the calcaneus has fewer uncertainties than other bone sites. Separation of activities involving only walking as compared with those that include some jogging or running forms a natural method of selecting for "low" vs "high" load activity in terms of calcancal peak force levels. Because of differences in the mechanisms of walking and jogging, the peak ground reaction forces while walking range from one to 1.5 body weights (BW) $(10,23)$ and from 2 to 3 BW while jogging (9). The low-load (LL) group consisted of those who recorded only walking and LL exercise during the study. The LL group engaged in activities for which the peak vertical component of the ground reaction force $\left(G R F_{y}\right)$ supported by one leg is normally below approximately $1.5 \mathrm{BW}$, although a few load cycles above this level may occur during a typical day. Examples of LL activities include walking, swimming, cycling, 
TABLE 2. Anthropometric and physiologic data of all subjects ( $N=43$ ) divided into two groups based on their participation in exercise that imparted a $L L(N=15)$ or a $\mathrm{HL}(N=28)$ on the calcaneus.

\begin{tabular}{|c|c|c|c|}
\hline & $\begin{array}{c}\text { All } \\
(N=43)\end{array}$ & $\begin{array}{c}\text { Low } \\
(N=15)\end{array}$ & $\begin{array}{c}\text { High } \\
(N=28)\end{array}$ \\
\hline Age (yr) & $38.7 \pm 7.1$ & $39.5 \pm 7.5$ & $38.3 \pm 6.9$ \\
\hline Height (cm) & $177.9 \pm 6.0$ & $177.2 \pm 6.3$ & $178.3 \pm 5.8$ \\
\hline Body Mass (kg) & $78.7 \pm 7.8$ & $78.0 \pm 9.2$ & $79.0 \pm 7.1$ \\
\hline Body Mass Index $\left(\mathrm{ht}^{2} \cdot \mathrm{kg}{ }^{1}\right)$ & $24.9 \pm 2.3$ & $24.8 \pm 2.3$ & $24.9 \pm 2.3$ \\
\hline Right Foot Length $(\mathrm{cm})$ & $26.7 \pm 0.8$ & $26.3 \pm 0.8$ & $26.9 \pm 0.7$ \\
\hline Right Heel Thickness (cm)† & $5.2 \pm 0.3$ & $5.2 \pm 0.3$ & $5.2 \pm 0.3$ \\
\hline Right Heel Width $(\mathrm{cm}) \dagger t$ & $4.5 \pm 0.3$ & $4.5 \pm 0.2$ & $4.6 \pm 0.3$ \\
\hline $\begin{array}{l}\text { Right calcaneal bone mineral } \\
\text { density }\left(\mathrm{g} \cdot \mathrm{cm}^{2}\right)\end{array}$ & $0.643 \pm 0.077$ & $0.597 \pm 0.062$ & $0.668 \pm 0.074^{*}$ \\
\hline $\begin{array}{l}\text { Left calcaneal bone mineral } \\
\text { density }\left(\mathrm{g} \cdot \mathrm{cm}^{2}\right)\end{array}$ & $0.639 \pm 0.080$ & $0.591 \pm 0.058$ & $0.666 \pm 0.081^{*}$ \\
\hline Daily walking steps per leg & $3951 \pm 1267$ & $3643 \pm 1131$ & $4116 \pm 1324$ \\
\hline Minutes per week of any exercise & $167(0-772) \S$ & $31(0-142) \S$ & $216(15-772) \S$ \\
\hline \multicolumn{4}{|c|}{$\begin{array}{l}\text { Values are mean } \pm \mathrm{SD} \text {. } \\
\dagger \text { Anterior/posterior (obtained from scanner nine row average). } \\
\text { †† Medial/lateral (measured with calipers). } \\
P<<0.004 \text { l low vs high. }\end{array}$} \\
\hline
\end{tabular}

and weightlifting. Weightlifting as a LL exercise may seem contradictory, but none of the subjects in this study participated in weightlifting activities that significantly load the calcaneus. The high-load (HL) group consisted of subjects whose activities imparted single leg peak $\mathrm{GRF}_{\text {, }}$ of $2 \mathrm{BW}$ or greater such as jogging, volleyball, basketball, and racquetball. We required that the types of activities, i.e., LL and $\mathrm{HL}$ recorded during the study be consistent with the subjects' 6-month (taken during week 3 ) and 1-yr histories (taken during week 1).

Data were stored on a personal computer and analyzed using Primer (6) and Mystat (Systat, Inc., Evanston, IL). Analyses included standard descriptive statistics (mean, median, standard deviation, and range), analysis of variance (ANOVA), and simple linear correlations. We required a $P<0.05$ level for significance.

\section{RESULTS}

The anthropometric and physiologic data for the 43 subjects are presented in Table 2 . The main source of quantitative data was the 7 -d $\log$ card. It provided daily walking steps and information on the date, type, and duration of exercise activity occurring during the week. The cards were preferred to the detailed pocket log book that provided more information than was needed. Subject compliance, evaluated during weekly interviews, was remarkably good. Only 4 of 53 , or $7.5 \%$, of our subjects turned in unreliable records.

\section{Subject Occupations}

The subjects lived and worked in the area surrounding NASA Ames Research Center which is located a few miles north of San Jose, CA and 40 miles south of San Francisco, CA. Forty-four percent $(N=19)$ of the group
TABLE 3. Types of exercise recorded by low and high calcaneal loaders during the nine week study.

\begin{tabular}{|c|c|c|}
\hline Type of Exerciset & $\begin{array}{l}\text { Low } \\
N=15\end{array}$ & $\begin{array}{l}\text { High } \\
N=28\end{array}$ \\
\hline Jogging & $* * *$ & 21 \\
\hline Cycling & 2 & 15 \\
\hline Weightlifting & 2 & 13 \\
\hline Swimming & 2 & 6 \\
\hline Volleyball & $* * *$ & 5 \\
\hline Soccer & $\star \star \star *$ & 4 \\
\hline Hiking & 1 & 4 \\
\hline Tennis & $* * *$ & 4 \\
\hline Softball & $* * *$ & 5 \\
\hline Basketball & $* *$ & 2 \\
\hline Raquetball & $\approx * \star$ & 2 \\
\hline Golf & 0 & 2 \\
\hline Aerobics & *** & 4 \\
\hline $\begin{array}{l}\text { Home exercises (LL) } \\
\text { (Nordic Track; } \\
\text { Stairmaster; Yoga; } \\
\text { push-ups, sit-ups, etc.) }\end{array}$ & 5 & 11 \\
\hline
\end{tabular}

were either engineers or worked in engineer or computer related occupations. An additional $21 \%(N=9)$ of our subjects were in various management positions, sales, accounting, or other aspects of business. The remaining 15 subjects had a variety of occupations including two machinists, three students, a minister, and a park ranger.

Thirty-two subjects had occupational activities described as "desk" jobs. The remaining 11 had occupations that may have required periodic increases in physical activity levels (i.e., restaurant worker and firefighters). During the workday, physical activity was quantified only in terms of walking steps and, therefore, did not account for occasional daily $\mathrm{GRF}_{\mathrm{z}}$ exceeding 1.5 BW that may have occurred. All subjects' 6-month and 1 -yr histories were consistent with their 9 wk of selfreported activities.

\section{Types of Physical Activities}

The LL group was composed of 15 subjects: 8 subjects reported no exercise and 7 reported only LL exercise as defined previously. Twenty-eight subjects reported HL activity. Twenty-four of the subjects in the HL group also recorded some participation in LL activities. Table 3 lists the most common types of exercises performed during the study. Most subjects participated in more than one exercise activity with jogging $(N=21)$, cycling $(N=$ $17)$, and weightlifting $(N=15)$ being the three most popular. Only four HL subjects reported participation in only one activity, jogging $(N=3)$ and tennis $(N=1)$.

\section{Steps or Walking Load Cycles}

The subjects walked an average of $7902 \pm 2534$ steps (mean \pm SD) (total of both legs) or approximately equal to $3.9 \pm 1.2 \mathrm{miles} \cdot \mathrm{d}^{-1}$, estimated from individual subject step length measurements obtained at the beginning of the study during controlled normal walking trials. Steps 


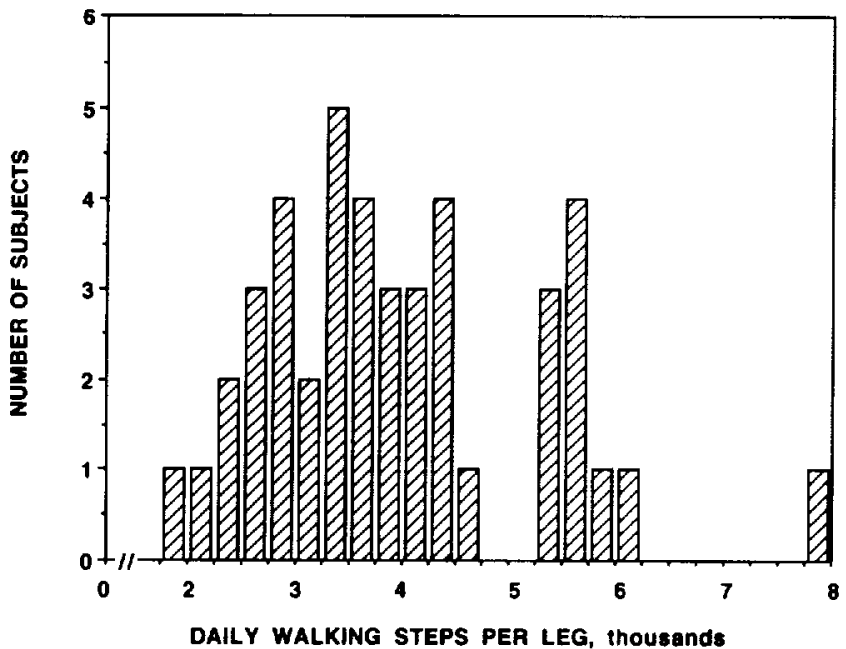

Figure 1-Frequency distribution of number of daily walking steps (load cycles) per leg.

walked per leg per day among all subjects ranged from 1907 to 7819 steps, a fourfold difference (Fig. 1). There was no significant difference in daily walking steps between HL and LL groups (Table 2). The average weekday steps per leg $\left(3949 \pm 1335\right.$ cycles $\left.\cdot \mathrm{d}^{-1}\right)$ and the average weekend steps $\left(3948 \pm 1353 \mathrm{cycles} \cdot \mathrm{d}^{-1}\right)$ were remarkably similar. Individual activity patterns accounted for a coefficient of variation for daily steps of $35.9 \%$ while a $7-\mathrm{d}$ random sample had a daily variation of $39.6 \%$. Week to week (weekly) variation in steps was half the daily variation or $18.0 \%$. The average number of daily steps was not related to time spent in nonwalking physical activities for all subjects $(r=0.13, \mathrm{NS})$ or in either load group (LL: $r=0.05$, NS; HL: $r=0.04$, NS).

\section{Duration of Nonwalking Exercise Activities}

We elected to express exercise duration in terms of minutes rather than load cycles because of the uncertainties in converting from exercise minutes to exercise load cycles. When all 35 subjects ( $7 \mathrm{LL}$ and $28 \mathrm{HL}$ ) engaged in some form of nonwalking exercise (activities where the stepmeter could not be worn, e.g., running/jogging, cycling, swimming, weightlifting, racquet sports, etc.) are considered together, $143(2-772) \mathrm{min} \cdot \mathrm{wk}^{-1}$ were spent exercising in either LL or HL activity. The seven men in the LL group who reported some exercise activity during the 9-wk study spent $31(2-142) \mathrm{min} \cdot \mathrm{wk}^{-1} \mathrm{me}-$ dian (range) in LL (nonwalking) exercise. The HL group spent $216(15-772) \mathrm{min} \cdot \mathrm{wk}^{-1}$ in all types of exercise. Fifty-one percent of this time, or $110 \mathrm{~min} \cdot \mathrm{wk}^{-1}$, was spent in activities generating high lower body forces (peak $\mathrm{GRF}_{z} \geq 2.0 \mathrm{BW}$ ).

Inconsistency of exercise among subjects accounted for a large daily and somewhat smaller weekly variation in time spent exercising. The mean coefficient of variation $( \pm S D)$ for daily minutes of any type of exercise

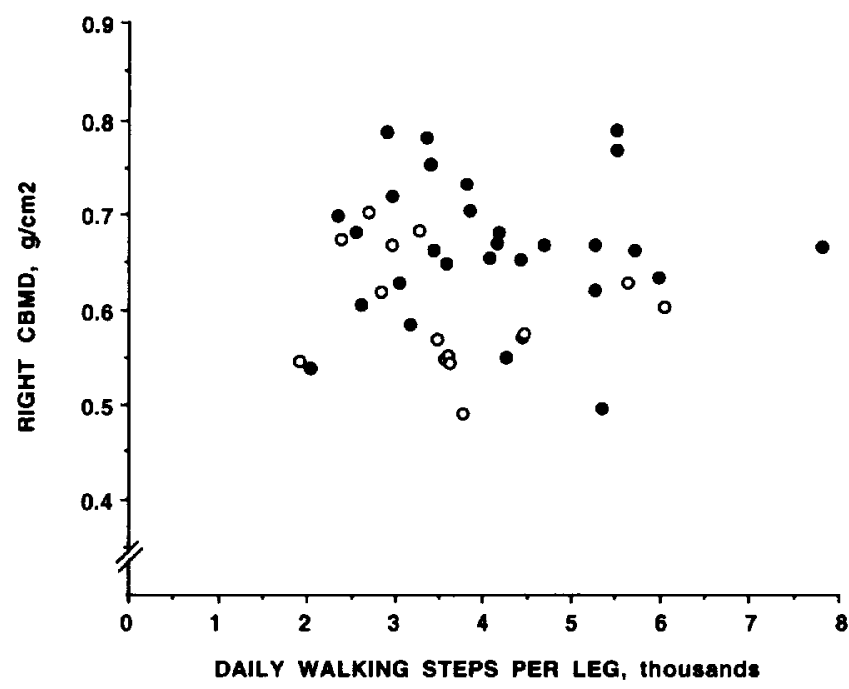

Figure 2-Relationship of right CBMD to daily walking steps (load cycles) per leg in $\mathrm{HL}(O)$ and $L L(C)$ subjects $(N=43 ; r=0.03$, NS).

among subjects reporting some exercise activity $(N=35)$ was $199 \%( \pm 144 \%)$, significantly higher $(P<0.045)$ than the daily variation computed from a 7 -d random sample (coefficient of variation equal to $140 \% \pm 91 \%$ ). The mean coefficient of variation computed for weekly variation in all exercise activity was reduced to $80 \%$ $( \pm 67 \%)$. Considering the HL group separately, the mean coefficient of variation for daily HL exercise was $229 \%$ $( \pm 142 \%)$. The weekly variation in minutes in HL activity was $87 \%( \pm 67 \%)$.

\section{Calcaneal Bone Mineral Density}

The mean calcaneal bone mineral density (CBMD) for all 43 subjects was statistically similar on the right and on the left: $0.643 \pm 0.077$ and $0.639 \pm 0.080 \mathrm{~g} \cdot \mathrm{cm}^{-2}$, respectively. The values are the average of all measurements taken of each calcaneus. Right CBMD was not related to the number of daily walking steps (Fig. 2) or body weight in any of the groups. As shown in Table 2 the right CBMD was $12 \%$ higher in the HL group than the LL group $(P<0.004)$.

No significant correlation was found between CBMD and exercise minutes in the LL group ( $\mathrm{r}=-0.18$, NS), between CBMD and total exercise minutes in the HL group ( $r=0.33$, NS), nor between CBMD and only the LL minutes of excrcise in the HL group $(r=0.08, N S)$. HL minutes of exercise in the HL group was related to CBMD ( $\mathrm{r}=0.41, P<0.03$; Fig. 3 and Table 4 ).

\section{DISCUSSION}

The results of this study support the concept that the dominant factor in daily physical activity relating to bone mineral density is the participation in site specific HL activities, i.e., for the calcaneus, high calcaneal loads. Mean values for CBMD were higher in the 28 subjects 


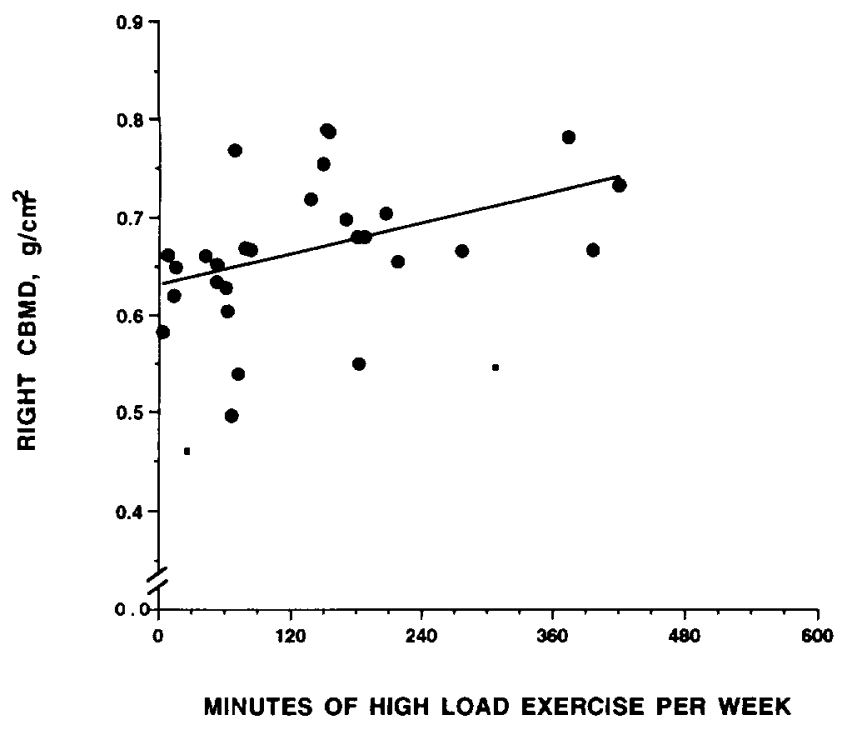

Figure 3-Relationship of right CBMD to HL minutes of exercise per week in the HL group $(N=28, r=0.41, P<0.03)$.

TABLE 4. Correlation coefficients for the mineral density of the right calcaneus in all subjects $(N=43), \mathrm{LL}(N=15)$, and $\mathrm{HL}(N=28)$.

\begin{tabular}{|c|c|c|c|}
\hline & $\begin{array}{l}\text { All } \\
\text { (r) }\end{array}$ & $\begin{array}{l}\text { Low } \\
\text { (r) }\end{array}$ & $\begin{array}{c}\text { High } \\
\text { (r) }\end{array}$ \\
\hline Height $(\mathrm{cm})$ & 0.23 & 0.09 & 0.31 \\
\hline Body mass (kg) & 0.18 & -0.15 & 0.36 \\
\hline Body mass index $\left(\mathrm{ht}^{2} \cdot \mathrm{kg} \cdot 1\right)$ & 0.03 & -0.29 & 0.17 \\
\hline Right foot length $(\mathrm{cm})$ & 0.24 & 0.24 & -0.02 \\
\hline Right heel thickness $(\mathrm{cm}) \dagger$ & 0.24 & 0.19 & 0.28 \\
\hline Right heel width (cm)†† & 0.004 & 0.33 & -0.23 \\
\hline Daily walking steps per leg & 0.03 & -0.18 & 0.01 \\
\hline Minutes per week of $L L$ exercise & - & -0.18 & 0.08 \\
\hline Minutes per week of HL exercise & - & - & $0.41^{*}$ \\
\hline
\end{tabular}

who reported participation in activities that imparted single leg peak $\mathrm{GRF}_{z} \geq 2 \mathrm{BW}$ than in the 15 subjects who did not. In addition, we found a significant correlation of CBMD to time spent in HL activities. CBMD did not correlate to number of daily walking steps in all subjects or in either of the two loading groups.

Expressed in miles, this population of 43 men (age 26-51) averaged approximately 3.9 miles of walking per day. An individual weekly variation of $18 \%$ in walking steps indicated a rather consistent pattern of week-toweek "walking type" activity. Our results are slightly lower than the 6 and 5.6 miles $\cdot \mathrm{d}^{-1}$ reported by Mazess and Barden (8) and Kanders et al. (7) in women aged 20-39. The lack of relationship between walking steps and CBMD are more or less consistent with what has been reported elsewhere, although very few studies have examined only walking in relation to bone density, and of these only one examined calcaneal bone mineral density (4). Cavanaugh and Cann (1) found that a 1-yr brisk walking program did not prevent the loss of spine vertebral bone density in early post menopausal women.
Mazess and Barden (8) also reported no significant relationship between lumbar, femur, radius, or humerus BMD and daily walking distance. In contrast, Zylstra et al. (25) found that femoral neck and lumbar spine densities increased with estimated daily walking hours. Kanders et al. (7) also suggested that walking could increase spine density by increasing daily energy expenditure which they correlated to vertebral bone density in a group of women. In these studies the investigators did not limit their subject population to just walkers. The subjects were also permitted to participate in daily activities such as jogging that impose significantly higher forces on the spine than walking. It is also quite difficult to control subject groups based on spine loading since common activities such as lifting can exert compressive forces on the spine 2-4 times greater than during walking $(11,14)$. The calcaneus does not have these same limitations because the forces imposed on it are highly correlated to the level of the ground reaction force.

While daily walking duration (steps or load cycles) was not a significant contributor to calcaneal bone density in men during midlife, walking duration and walking "intensity" may contribute to bone density in other subject populations. As walking becomes the main and often the only activity with advancing age, differences in walking intensity, measured in this context in terms of ground reaction force levels, and duration may become more dominant factors in skeletal loading and musculoskeletal remodeling (20).

In our relatively small group of normal, healthy men with similar shoe size, we found no relationship between calcaneal bone density and body weight. CBMD is wellknown to correlate to body weight in large populations (24) and to a broad range of body weights (12). Other studies that have not found correlations with body weight have suggested that intensity of activity partially masks the effects of body weight $(2,16)$.

Records of time spent in HL activity of the calcaneus proved to be the most effective means of associating daily physical activity level with its bone density. While our results emphasize the role of HL exercise duration, an important point to note is that in most cases the minutes recorded and plotted in the figures overestimate the actual amount of time spent performing HL activity. In addition, the levels of $\mathrm{GRF}_{\mathrm{z}}$ generated during exercise vary according to the individual and the intensity of the activity. We elected not to subtract walking and rest periods from some of the activities engaged in by the subjects, e.g., softball and soccer, because of uncertainties in accurately estimating the length of these periods.

The influence of physical activity on CBMD has been investigated by others. A 9-month training program resulted in small, but significant, increases in CBMD for consistent runners preparing for a marathon (22). In another study $2 \mathrm{~h} \cdot \mathrm{wk}^{-1}$ of combined low and some high load exercise maintained calcaneal bone density in a 
population of 70 - to 79 -yr-olds (13). Cheng et al. (2) reported that several measures of activity level correlated positively with CBMD. Women (50-60 yr) who exercised "vigorously" with high and low calcaneal load activities two or more times per week had higher calcaneal volumetric $\left(\mathrm{g} \cdot \mathrm{cm}^{-3}\right)$ bone density.

Our results agree with others who have proposed the calcaneus as a relevant bone site for monitoring physical activity and skeletal integrity $(3,19)$. With the exception of Ward's triangle, CBMD loss rates with age are higher than any other bone site and CBMD also correlates significantly with bone density and fracture risk assessment of clinically important trabecular regions $(15,18)$. Therefore, monitoring calcaneal bone density and daily ground reaction force histories may provide a noninvasive method of investigating the influence of mechanical forces on the functional adaptation of bone. However, to

\section{REFERENCES}

1. Cavanaugh, D. J. and C. E. Cann. Brisk walking does not stop bone loss in postmenopausal women. Bone 9:201-204, 1988.

2. Cheng, S., H. Suominen, T. Rantanen, T. Parkatt, and E. HelkKINEN. Bone mineral density and physical activity in 50-60-yearold women. Bone Miner, 12:123-132, 1991.

3. Cummings, S. R., D. M. Black, M. C. Nevitt, et al. Appendicular bone density and age predicts hip fracture in women. JAMA 263:665-668, 1990.

4. Dalfo, N. and K. E. Olsson. Bone mineral content and physical activity. Acta Orthop. Scand. 45:170-174, 1974.

5. Donaldson, C. L., S. B. Hulley, J. M. Vogel, R. S. Hattner, J. H. BAYERS, and D. E. McMillan. Effect of prolonged bed rest on bone mineral. Metabolism 19:1071-1084, 1970.

6. Glantz, S. Primer of Biostatistics. New York, McGraw-Hill, 1987, pp. 30-55.

7. Kanders, B., D. W. Dempster, and R. Lindsay. Interaction of calcium nutrition and physical activity on bone mass in young women. J. Bone Miner. Res. 3:145-149. 1988.

8. Mazess, R. B. and H. S. BARden. Bone density in premenopausal women: effects of age, dietary intake, physical activity, smoking, and birth-control pills. Am. J. Clin. Nutr. 53:132-142, 1991.

9. MCMAHON, T. A. and G. C. Cheng. The mechanics of running: how does stiffness couple with speed. J. Biomech. 23:65-78, 1990.

10. Mochon, S. and T. A. Mc Mahon. Ballistic walking. J. Biomech. 13:49-57, 1979.

11. NaChEMSON, A. Towards a better understanding of low-back pain: a review of the mechanics of the lumbar disc. Rheumatol. Rehabil. 14:129-143, 1975.

12. Roberts, J. G., E. Ditomasso, and C. E. Weisbek. Photon scattering measurements of calcaneal bone density: results of in vivo crosssectional studies. Radiology 17:20-28, 1982.

13. Rundgren, Å., A. Aniansson, P. Luengberg, and H. Wetterqvist. Effects of a training programme for elderly people on mineral content of the heel bonc. Arch. Gerontol. Geriatr. 3:243-248, 1984.

14. Schultz, A., G. B. J. Andersson, R. Ortengiren, R. Bjork, and M. Nordin. Analysis and quantitative myoelectric measurements of apply quantitative models (21) expressing bone density in terms of daily loading histories, force monitoring instrumentation will need to be developed since individuals experience a wide range of $\mathrm{GRF}_{z}$ throughout the day.

The authors acknowledge the significant contribution of the subjects who participated in this study. We are indebted to D. O'Hara, R.N., manager of the Human Research Facility at NASA Ames Research Center, for monitoring and coordinating the 9-wk study and to Don Wadsworth for the collection of the calcaneal mineral density data. We would also like to thank K. Jackson, Ph.D., for helpful discussions.

This work was funded by grants from the Musculoskeletal Research Program at NASA Ames Research Center, project numbers 199-26-12-02 and 199-26-12-36.

This work was presented in part at the 40th Annual Meeting of the American College of Sports Medicine.

Address correspondence to: Teresa Hutchinson, Life Sciences Division (MS: 239-11), NASA Ames Research Center, Moffett Field, CA 94035-1000.

loads on the lumbar spine when holding weights in standing postures. Spine 7:390-397, 1982 .

15. Steiger P., S. R. Cummings, D. M. Black, N. E. Spencler, and H. K. Gennnt. Age-related decrements in bone mineral density in women over 65. J. Bone Miner. Res. 7:625-632, 1992.

16. Suominen, H., E. Heikkinen, P. Vainio, and T. Lahtinin. Mineral density of calcaneus in men at different ages: a population study with special reference to life-style factors. Age Ageing 13:273281,1984 .

17. TAYiok, H. L., D. R. Jacobs JR., B. Schucker, J. Knudsen, A. S. Leon, and G. Debacker. A questionnaire for the assessment of leisure time physical activities. J. Chron. Dis 31:741-755, 1978.

18. Vogel. J. M., J. W. Davis, P. D. Russ, and R. D. Wasnich. Uniformity of bone mineral content across eight skeletal measurement sites. In: C. Christiansen and K. Overgaard. (Eds.). Osteopress, ApS. 1990, pp. 631-633.

19. Vociel, J. M., R. D. WASNICH, and P. D. Ross. The clinical relevance of calcaneus bone mineral measurements: a review. Bone Miner. 5:35-58, 1988.

20. Whalen, R. T. and D. R. Cartek. The influences of declining activity level with age on bone density. Orthop. Res. Soc. Trans. 36th Ann. 15:565, 1990.

21. WhAtER, R. T., D. R. CarTER, and C. R. Stetele. Influence of physical aclivity on the regulation of bone density. J. Biomech. $21: 825-837,1988$

22. Williams, J. A., J. Wagner, R. Wasnich, and L. Heilbrun. The effect of long-distance running upon appendicular bone mineral content. Med. Sci. Sport Exerc. 16:223-227, 1984.

23. WINTER, D. A. The biomechanics and motor control of human gait. Waterloo: University of Waterloo Press, 1987, pp. 29-43.

24. Yano K., L. K. Heil Brun, R. D. Wasnich, J. H. Hankin, and J. M. Voitl. The relationship between diet and bone mineral content of multiple skeletal sites in elderly Japanese-American men and women living in Hawaii. Am. J. Clin. Nutr. 42:877-888, 1985.

25. Zrisira, S., A. Hopkins, M. Erk, M. M. Hreshchysiyn, and M ANBar. Effect of physical activity on lumbar spine and femoral neck bone densities. Int. J. Sports Med. 10:181-186, 1989. 